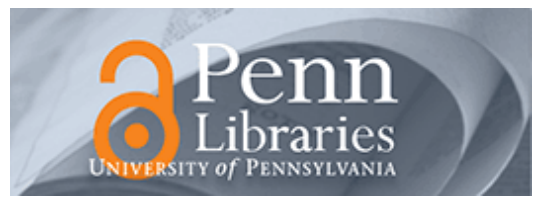

University of Pennsylvania ScholarlyCommons

$9-2014$

\title{
Aiding Decision Making to Reduce the Impacts of Climate Change
}

Howard Kunreuther

University of Pennsylvania

Follow this and additional works at: https://repository.upenn.edu/oid_papers

Part of the Behavioral Economics Commons, Other Earth Sciences Commons, and the Other Life Sciences Commons

Recommended Citation

Kunreuther, H. (2014). Aiding Decision Making to Reduce the Impacts of Climate Change. Journal of Consumer Policy, 37 (3), 397-411. http://dx.doi.org/10.1007/s10603-013-9251-z

This paper is posted at ScholarlyCommons. https://repository.upenn.edu/oid_papers/8

For more information, please contact repository@pobox.upenn.edu. 


\title{
Aiding Decision Making to Reduce the Impacts of Climate Change
}

\author{
Abstract \\ Utilizing theory and empirical insights from psychology and behavioural economics, this paper examines \\ individuals' cognitive and motivational barriers to adopting climate change adaptation and mitigation \\ measures that increase consumer welfare. We explore various strategies that take into account the \\ simplified decision-making processes used by individuals and resulting biases. We make these points by \\ working through two examples: (1) investments in energy efficiency products and new technology and (2) \\ adaptation measures to reduce property damage from future floods and hurricanes. In both cases there is \\ a reluctance to undertake these measures due to high and certain upfront costs, delayed and probabilistic \\ benefits, and behavioural biases related to this asymmetry. The use of choice architecture through \\ framing and the use of default options coupled with short-term incentives and long-term contracts can \\ encourage greater investment in these measures.

\section{Keywords} \\ Climate change, decision processes, behavioural economics, energy efficiency, mitigation and adaptation \\ measures, choice architecture \\ Disciplines \\ Behavioral Economics | Other Earth Sciences | Other Life Sciences
}


NBER WORKING PAPER SERIES

AIDING DECISION-MAKING TO REDUCE THE IMPACTS OF CLIMATE CHANGE

\author{
Howard Kunreuther \\ Elke U. Weber \\ Working Paper 19776 \\ http://www.nber.org/papers/w19776
}

NATIONAL BUREAU OF ECONOMIC RESEARCH
1050 Massachusetts Avenue
Cambridge, MA 02138
January 2014

Support for this research comes from the National Science Foundation (SES-1061882 and SES-1062039); the Center for Climate and Energy Decision Making through a cooperative agreement between the National Science Foundation and Carnegie Mellon University (SES-0949710); the Center for Risk and Economic Analysis of Terrorism Events (CREATE) at the University of Southern California; the Center for Research on Environmental Decisions (CRED; NSF Cooperative Agreement SES-0345840 to Columbia University) and the Wharton Risk Management and Decision Processes Center. We thank Jim Poterba and anonymous referees for helpful comments and Carol Heller for editorial assistance. The views expressed herein are those of the authors and do not necessarily reflect the views of the National Bureau of Economic Research. Authors' names are in alphabetical order.

NBER working papers are circulated for discussion and comment purposes. They have not been peerreviewed or been subject to the review by the NBER Board of Directors that accompanies official NBER publications.

(C) 2014 by Howard Kunreuther and Elke U. Weber. All rights reserved. Short sections of text, not to exceed two paragraphs, may be quoted without explicit permission provided that full credit, including (C) notice, is given to the source. 
Aiding Decision-Making to Reduce the Impacts of Climate Change

Howard Kunreuther and Elke U. Weber

NBER Working Paper No. 19776

January 2014

JEL No. D03,Q41,Q42,Q54

\begin{abstract}
$\underline{\text { ABSTRACT }}$
Utilizing theory and empirical insights from psychology and behavioral economics, this paper examines individuals' cognitive and motivational barriers to adopting climate change adaptation and mitigation measures that increase consumer welfare. We explore various strategies that take into account the simplified decision-making processes used by individuals and resulting biases. We make these points by working through two examples: (1) investments in energy efficiency products and new technology and (2) adaptation measures to reduce property damage from future floods and hurricanes. In both cases there is a reluctance to undertake these measures due to high and certain upfront costs, delayed and probabilistic benefits and behavioral biases related to this asymmetry. The use of choice architecture through framing and the use of default options coupled with short-term incentives and long-term contracts can encourage greater investment in these measures.
\end{abstract}

Howard Kunreuther

Operations and Information Management

The Wharton School

University of Pennsylvania

3730 Walnut Street, 500 JMHH

Philadelphia, PA 19104-6366

and NBER

kunreuther@wharton.upenn.edu

Elke U. Weber

Center for Research on Environmental Decisions

Uris Hall 716, 3022 Broadway

New York, NY 10027-6902

euw2@columbia.edu 


\section{Introduction}

This paper examines how individuals respond to climate change risks relative to what is predicted by formal models of choice, and proposes strategies for aiding and improving decisions. We focus on two areas where consumers are reluctant to incur the costs of mitigation and adaptation measures that will increase their welfare, as illustrated by the following two climate change response measures.

Adopting Energy Efficient Products and Other New Technologies. Individuals underinvest in measures that will reduce greenhouse gas (GHG) emissions even when the expected discounted benefits of these measures exceed their expected costs (Creyts, Granade, and Ostrowski 2010). There has been a reluctance by many consumers to purchase energy-efficient appliances and switch from incandescent to CFL bulbs where the economic benefits in the form of lower electricity bills greatly exceed the extra costs of these products (Hausman 1979; Gately 1980; Mills and Schleich 2008). ${ }^{2}$ This difference between the optimal and actual level of energy consumption has been termed the energy efficiency gap (Hirst and Brown 1990; Jaffe and Stavins 1994). In addition, few homeowners have invested in new technologies such as solar panels even when the cost of installing these technologies are less than the expected discounted savings in energy costs over time as indicated by recent studies (Denholm et al. 2009; Drury et al. 2013).

Investing in Adaptation Measures to Reduce Flood-Related Losses. Few homeowners residing in areas subject to flood-related losses from hurricanes and riverine flooding voluntarily invest in measures that reduce future losses, even when they would find these measures to be cost-effective (Kunreuther, Meyer and Michel Kerjan 2013). In a survey of over 500 residents in coastal counties during Hurricane Sandy in 2012, a great majority of respondents indicated doing at least one storm preparation activity, such as buying batteries and food and water reserves. But those were mainly short-term preparation actions that required limited effort. Many fewer households undertook more substantial protective measures. For instance, fewer than half of storm shutter owners in

\footnotetext{
${ }^{2}$ Some individuals prefer incandescent to CFL bulbs because they light up immediately and provide better lighting.
} 
New York State who responded to the survey actually installed them to protect their windows before the hurricane (Meyer et al. 2013).

When individuals take steps to mitigate GHG emissions by investing in energy efficient products and/or new technologies, they are having a positive impact on the global community. Residents who undertake adaptive measures to reduce losses from future flood-related disasters are reducing the need for federal disaster relief expenditures. Although we will not be examining the social welfare impacts associated with mitigation and adaptation measures, this factor plays a role in government decisions to encourage individuals to undertake specific actions to deal with climate change. ${ }^{3}$

The paper proceeds as follows. Section 2 characterizes the decision processes of four hypothetical families, two of whom are concerned with whether to invest in new technologies that will reduce their use of carbon-based fuel, and two of whom are considering whether to elevate their homes to reduce future flood damage. Using these examples we delineate features of descriptive models of choice with respect to decisions to undertake investments that reduce future costs, and highlight how these characterizations of behavior differ from normative models of choice.

Section 3 discusses the concepts of intuitive and deliberative thinking and how they apply to investing in adaptation or mitigation measures related to climate change. Section 4 explores potential modifications to the choice environment, and other policy actions, that may affect consumer choices in mitigating or adapting to climate change and its impacts. The concluding section summarizes the paper and suggests directions for future research.

\footnotetext{
${ }^{3}$ In this regard, Borenstein (2012) emphasizes the need to develop cost estimates of the associated environmental and non-environmental externalities of existing technologies for generating electricity so that one can compare the use of coal and gas against renewable energy technologies-wind, solar and biomass.
} 


\section{Individuals' Decision Making Processes}

The following four hypothetical and stylized examples based on actual accounts highlight the challenges in incentivizing individuals to invest in mitigation and adaptation measures that reduce the impacts of climate change:

\subsection{Mitigation Actions}

The Watt family in Santa Barbara California is considering whether to spend $\$ 15,000$ to install solar panels on their home that promise to reduce their average annual energy expenditures by somewhere between $\$ 3,000$ and $\$ 6,000$ over their current system. Solar panels will allow them to lock in long-term electricity rates and protect them from large increases should on-grid utility prices soar due to possible climate change repercussions. The family compared the cost of solar panels with their expected savings in energy expenditures over the next several years, and concluded that it was not worth spending the money on the solar panels. Furthermore, they are concerned with the negative impact that a $\$ 15,000$ investment would have on their limited budget during the year. They are unconcerned about the magnitude and impact of climate change in the next 20 years, and so decide not to invest in the solar panels now.

The Winter family in Juneau, Alaska experienced a 45-day power failure in 2008, after a large avalanche destroyed a section of the main hydroelectric transmission line in the city. Backup generators using diesel fuels were the only source of electricity causing electricity prices to increase by 500 percent. To save money, the family reduced their energy consumption by taking measures such as turning down the heat and switching to CFL bulbs. It is not clear whether they will continue to undertake these steps for conserving energy in the future.

\subsection{Adaptation Actions}

The Lowland family recently moved to a home on the shores of the Mississippi River and is considering whether to invest $\$ 1,200$ in flood-proofing their home so it is less susceptible to water damage from future flooding. Hydrologists have estimated that the 
annual chance of a severe flood affecting their home is $1 / 100$. Should such a disaster occur, the reduction in damage from flood proofing the home is expected to be $\$ 40,000$. The Lowland family does not believe that it is worth incurring the cost to flood-proof their home since they perceive the risk of flooding to be below their threshold level of concern even with the possibility of sea level rise due to climate change. They see other ways of spending the $\$ 1,200$ investment cost and believe that if they suffer severe damage to their property and contents, the federal government will bail them out with grants and very low interest loans.

The Waterton family in Cornwall, UK experienced several incidents of flooding from major rainfall and storms that caused damage to their home and others in the community due to runoffs that exceeded the capacity of drainage infrastructure. Because of these recent events, they have decided to invest in flood adaptation measures to protect themselves again future losses.

\subsection{Comparisons}

The Watt and Lowland families are reluctant to incur the costs associated with investing in adaptive measures for the following reasons:

- They believe that climate change will not impact them in the near future.

- The impact of the immediate upfront costs of undertaking these investments will impact on other expenditures given budget constraints.

The Winter and Waterton families are interested in taking steps to reduce their energy consumption and protect themselves against flooding, for the following reasons:

- The respective incidents in Juneau and Cornwall make the potential impacts of climate change salient to them.

- They focus on the immediate potential benefits from investing in these measures. 


\section{Intuitive and Deliberative Thinking}

Daniel Kahneman in his Nobel address (2003) and book Thinking, Fast and Slow (2011) characterizes two modes of thinking as "System 1" and "System 2" by building on a large body of cognitive psychology and behavioral decision research. The intuitive System 1 operates automatically and quickly with little or no effort and no sense of voluntary control. It uses simple associations (including emotional reactions) that have been acquired from personal experience with events and their consequences. The deliberative System 2 initiates and executes effortful and intentional mental operations as needed, including simple or complex computations or formal logic.

Many of the decision rules that characterize human judgment and choice under uncertainty utilize intuitive (System 1) processes that take advantage of past personal experiences, with their emotional reactions and other associations. Such shortcuts require less time and effort than a systematic analysis of the trade-offs between choice options and often lead to reasonable outcomes. If one takes into account the constraints on time, attention, and processing-capacity of decision makers, reliance on these intuitive decision processes may be the best we can do left to our own devices for many choices under uncertainty (Simon 1957).

Intuitive processes work well when decision makers have copious data on the outcomes of different decisions and recent experience is a meaningful guide for the future, as would be the case in stationary environments (Weber 2006). These processes do not work well, however, for low-probability high-consequence events for which the decision maker has limited or no past experience by definition. In such situations, reliance on intuitive processes for making decisions will most likely lead to focusing on the recent past and thus maintaining the status quo (Hertwig et al. 2004). This suggests that intuitive decisions are problematic in dealing with mitigation and adaption measures such as investing in solar energy or protecting one's house against future flood damage.

The methodologies that characterize deliberative (System 2) thinking require stakeholders to make choices in a more systematic manner. Deliberative processing focuses on all potential short- and long-term consequences and their likelihoods, and evaluates the options under consideration. Deliberative decisions are described by formal 
models where the optimal choice is made by individuals using criteria such as maximizing expected utility or by governments using the criterion of maximizing net present value. A challenge facing policy makers is to develop strategies that are based on formal models while recognizing the biases and simplified decision rules that characterize intuitive thinking.

\subsection{Evaluating Adaptation and Mitigation Decisions Using Deliberative Thinking}

It is instructive to evaluate the decisions by the two families in our examples in Section 2 who failed to take protective action. Deliberative thinking using a discounted expected utility $[\mathrm{E}(\mathrm{U})]$ model would have advised them to invest in these measures. Consider the Lowland family who was debating whether to invest in flood-proofing measures that will cost them $\$ 1,200$ but promised to reduce their losses by $\$ 40,000$ if a flood with an annual probability of $p=1 / 100$ occurred. If the family's wealth is currently $W$ and they plan to live in the house for the next $T$ years, the discounted $\mathrm{E}(\mathrm{U})$ of investing and not investing in flood-proofing is given by:

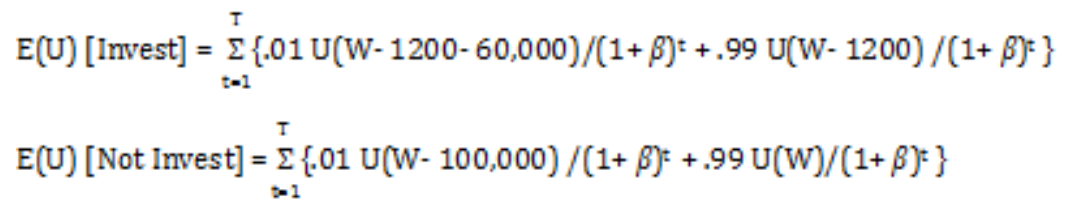

where $\beta=$ the annual discount rate, which is assumed to be constant over time.

If the Lowland family were risk neutral (i.e., if they perceived the costs and benefits of the two actions proportionally to their actual dollar values), and had accurate information on the probabilities, costs, and expected benefits from investing in floodproofing measures, they would choose to incur the $\$ 1,200$ even with a relatively high value $\beta=.10$ if they planned to live in their house for three or more years. ${ }^{4}$ They would still find this measure financially attractive even if they intended to move in the next

\footnotetext{
${ }^{4}$ Since $W$ is irrelevant when a person is risk neutral, the expected discounted benefits from investing in flood proofing when $\beta=.10$ is

$01 \sum_{r=1}^{T}(40,000) /(1.10)^{r}$

which exceeds $\$ 1,200$ when $\mathrm{T}>3$.
} 
couple of years if the property value of their home reflected the reduced losses in the future from their flood-proofing investment. If the family was risk averse and/or $\beta<.10$, they would find this adaptation measure even more attractive.

The Watt family would undertake a similar calculation to determine whether to invest $\$ 15,000$ in solar energy panels that would result in a reduction in their average annual energy bill of between $\$ 3,000$ and $\$ 6,000$ over their current system. Consider the case where the family's wealth is $W$ and their annual current annual electricity bill is $\$ 10,000$ per year. Suppose they would save only $\$ 3,000$ per year if they invested in solar energy and that their electricity bills would be constant over the next $T$ years. Then their decision on whether to invest would be determined by comparing the following two options and choosing the one which had the highest discounted $E(U)$ :

$$
\begin{aligned}
& \mathrm{E}(\mathrm{U}) \text { [Solar Panels] }=\sum_{\mathrm{t}=1}^{\mathrm{T}} \mathrm{U}(\mathrm{W}-7,000) /(1+\beta)^{\mathrm{t}}-15,000 \\
& \mathrm{E}(\mathrm{U})[\text { No Solar Panels }]=\sum_{i=1}^{\mathrm{T}} \mathrm{U}\left(\mathrm{W}^{*}-10,000\right) /(1+\beta)^{\mathrm{t}}
\end{aligned}
$$

If the Watt family planned to live in their house for only $T<5$ years, then the solar panel investment would not be worthwhile if the family was risk neutral, unless the property value increased significantly to reflect the savings in energy costs from this investment. If the annual savings from investing in solar panels exceeded $\$ 3,000$ then the investment would be financially attractive for values of $T<5$ years.

\subsection{Evaluating Adaptation and Mitigation Decisions Using Intuitive Thinking}

In designing mitigation and adaptation measures to reduce climate change risks, it is important to recognize the role that intuitive thinking plays in individuals' decision making processes. This section examines how risk perception and behavioral responses are guided by intuitive thinking. In this context, we highlight the role that past experience plays in the decision making process and its relevance to actions taken by the four families discussed in Section 2. 


\section{Perception of Climate Change Risks and Uncertainties}

Public perception of the risks of climate change differs from expert estimates

(Weber and Stern 2011). There has also been an increasing awareness of climate change as an uncertain phenomenon by the public and a growing realization that technological solutions and human responses have their own set of uncertainties (Patt and Weber, 2013).

Psychometric studies in many countries have shown that two dimensions influence people's intuitive perceptions of health and safety risks (Slovic 1987). The first factor, dread, captures emotional reactions to hazards like nuclear reactor accidents, or nerve gas accidents. Such hazards trigger people's automatic fear responses, often because of a perceived lack of control over exposure to the risks and because the consequences are perceived to be catastrophic. The second factor, unknowability, refers to the degree to which a risk (e.g., DNA technology) is perceived as scary because it is new, with unforeseeable consequences and with exposures not easily detectable. Both these reactions characterize perceptions of risk as more a feeling than a statistical concept (Peters and Slovic 2000; Loewenstein et al. 2001).

Intuitive perceptions of risk can lead to systematic deviations from expert assessments for risks that involve small probabilities and high degrees of uncertainty that do not trigger feelings of dread. Risks associated with climate change have these characteristics: their likelihood of adverse consequences is small and uncertain and they do not elicit strong fears in most people because they are abstract and have not been experienced personally (Weber 2006). To illustrate this point, consider the Lowland family. For them, the likelihood and consequences of a flood are abstract because they have never experienced a loss. In fact, they consider the chances of a flood causing damage to their home to be below their threshold level of concern.

Laypersons think about climate change in ways different than do climate scientists, including the use of different mental models (Kempton 1991; Bostrom et al. 1994). Many laypeople do not differentiate between climate and weather, and consider themselves experts on the weather. Hence, the risks associated with climate change are not viewed as new or uncontrollable (Bostrom et al. 1994; Cullen 2010). People feel that 
they have control over typical inclement weather by taking an umbrella to protect against rain, or by changing the location and timing of a planned outdoor wedding.

When climate change first emerged as a policy issue, people often confused it with the loss of stratospheric ozone resulting from releases of chlorofluorocarbon. As the "hole in the ozone layer" issue has receded from public attention, this confusion has become less prevalent (Reynolds et al. 2010). Today, greenhouse gases are often wrongly equated with more familiar forms of pollution, such as sulfur dioxide. People thus make the incorrect inference that "the air will clear" soon after emissions are reduced (Sterman and Sweeney 2007) when, in fact, most greenhouse gases continue to warm the planet for decades or centuries after they are emitted (Solomon et al. 2009). This leads individuals to underestimate the need for immediate action, which may contribute to why the Watt family decided not to invest in solar panels.

\section{Behavioral Responses to Losses and Delayed Consequences}

There are several other features of information processing that lead households such as the Watt and Lowland families to decide not to invest in adaptation and mitigation measures. Prospect theory formalizes the systematic observation that an outcome perceived as a loss relative to the status quo or other reference point is given greater weight than the same outcome perceived as a gain, a regularity labeled as loss aversion (Tversky and Kahneman 1991). In other words, people are much more averse to perceived costs than to foregone benefits. The upfront and certain costs of the solar panels and flood protection thus loom large for the Watt and Lowland families, much more prominently than the potential benefits of these investments down the road. ${ }^{5}$

\footnotetext{
${ }^{5}$ Loss aversion should motivate more action than would be undertaken using formal models of choice such as discounted expected utility theory. Climate change is typically framed as the loss of climateconditions that are conducive to human habitation on planet earth or more concretely as the loss of features (e.g., glaciers or coral reefs) or species (e.g., polar bears) that are highly valued by many people. This insight is being used by organizations like the Natural Resources Defense Council and the World Wildlife Fund that attempt to trigger loss aversion in their solicitations for charitable donations with images of doomed species (e.g., https://www.nrdcgreengifts.org/den-defender?s_src=CKGG-NRDC-GG-A02-S.DD-GGSE-SE-US-PLR-BO-ALL-Z00,

http://www.arctichome.com/showLBE.do?id=arcticHome\&type=pillar\&size=3\&exp=html\&). However, the effect of loss aversion to motivate actions is often counteracted by other factors. For example, most people do not find the threat of such losses credible, given that it is based on scientific predictions that are abstract and temporally distant rather than being personal and imminent (Weber, 2006).
} 
An additional explanation as to why individuals fail to invest in adaptation and mitigation measures in the face of transparent risks are budget constraints as illustrated by the Lowland and Watt families' unwillingness to incur the upfront costs of floodproofing and solar panels, respectively. Some budget constraints reflect financial reality, whereas others are psychological. Individuals tend to set up separate mental accounts for different classes of expenditures that serve as effective budgeting and self-control devices for decision makers with limited processing capacity and self-control (Thaler 1999).

Human temporal discounting tends to be quasi-hyperbolic, where outcome valuations fall very rapidly for even small delay periods (Laibson 1997). Observed discount rates from controlled experiments and field studies tend to be much larger than commercial interest rates (Frederick et al. 2002). This is yet another reason why the immediate upfront costs of mitigation and adaptation measures loom disproportionately large relative to their delayed expected benefits during the life of the property.

Another extreme form of discounting is myopic behavior where the decision maker focuses only on the potential benefits of an investment over the next $T$ periods (Kunreuther, Meyer and Michel-Kerjan 2013). If the decision makers' time horizon is only two or three years, then they will underweight the expected benefits of the investment when compared to a formal models of choice such as discounted expected utility theory that extends indefinitely into the future.

\section{Role of Past Experience}

The evidence is mixed on whether individuals learn from past experience with respect to investing in adaptation or mitigation measures that are likely to be costeffective. Even after the devastating 2004 and 2005 hurricane seasons in the U.S., a large number of residents in high-risk areas had still not invested in relatively inexpensive lossreduction measures, nor had they undertaken emergency preparedness measures (Goodnough 2006). This behavior contrasts with residents in Cornwall, UK who became concerned with climate change and were more open to undertaking mitigation and adaptation measures, perhaps because the local media linked the increase in rainfall intensity and flood risk to global warming (Spence et al. 2011). 
The Waterton family's investment in adaptation measures for dealing with the flood risk is similar to the decision by residents in California to buy earthquake insurance voluntarily following the 1989 Loma Prieta quake and the 1994 Northridge quake. In contrast to homeowners' insurance, earthquake coverage is not required as a condition for a mortgage, even in actively seismic states such as California. In the 1970s, less than 10 percent of the homes were insured against earthquake damage. By 1995, over 40 percent of the homes in many areas along the coast were insured against this risk (Palm 1995). There have been no severe earthquakes since 1985 and the percentage of residents that have earthquake insurance in 2012 has dropped back to 12 percent.

With regard to energy efficiency measures, there is empirical evidence that people develop energy-conservation habits when forced to take temporary measures in response to a power shortage or other disruption. The Winter family and other residents of Juneau, Alaska subsisted on a fraction of their previous energy budget for an extended period of time due to severed power lines. Response to this electricity "crisis" included electricity conservation that began within two days of the event and reduced electricity use by 25 percent over the period of supply disruption relative to the same period in 2007. After the transmission line was repaired and electricity rates returned to normal, electricity use increased but was still 8 percent below the usage during 2007 (Leighty and Meier 2010).

A second avalanche on January 9, 2009 damaged the same section of transmission line and caused a second supply disruption, albeit shorter in duration (19 vs. 45 days) and magnitude of price increase (200 vs. 500 percent). This time, energy usage during the disruption period decreased by 12 percent relative to the same period in 2007 and increased slightly ( 2 percent) after the disruption was over and prices went back to normal. Energy consumption over the next year was down 10 percent compared to the baseline in 2007 (Leighty and Meier 2010).

With respect to investment in solar technology, households such as the Watt family will be reluctant to incur the investment because of its high initial costs. Households like the Winter family are willing to incur the costs or inconvenience of curtailing their use of electricity following power shortages, in part because the financial savings are great during the emergency period, but also because new habits may get 
established during that period and the experienced costs or inconveniences of such curtailments may turn out to be not as large as anticipated.

\section{Strategies for Addressing Climate Change}

This section discusses how choice architecture as well as short-term economic incentives can affect individual choices with regard to energy efficiency and flood reduction.

\subsection{Choice Architecture and Economic Incentives}

Choice architecture, a term coined by Thaler and Sunstein (2008), indicates that people's choices often depend in part on how possible outcomes of different choice options are framed and presented. Framing typically refers to the way in which outcomes are described as gains or losses relative to a reference point, which can either be the status quo or another value. Choice architects can influence decisions by varying the reference point, the order in which alternatives and/or their attributes are presented, and can set one choice option as the no-choice default (see Johnson et al. 2012).

Most choice architecture interventions have focused on decisions where the outcomes are known with certainty or where there is a time delay. Adaptation and mitigation decisions with respect to climate change involve decisions under risk and uncertainty that require one to focus on the likelihood with which specific events might occur. An event with an extremely small likelihood and an outcome that does not elicit a strong affective reaction will tend to be ignored (i.e., treated as if it will not happen). Potential disasters attributed to climate change (such as flood damage from sea level rise) will tend to fall into this latter category, when described as statistical phenomena.

Economic incentives may complement choice architecture to increase the value of adaptation and mitigation investments that can reduce adverse climate change impacts. Long-term loans can spread the upfront costs over time, as a way to diminish individuals' real or psychological budget constraints. If the annual savings in the energy expenses from investing in solar energy are greater than the annual loan payments, adopting this technology will be financially attractive to homeowners. Similarly, if the annual loan 
payment for floodproofing one's home is less than the premiums for flood insurance due to lower expected claims payments, then it is a financially attractive adaptation measure.

\subsection{Encouraging Reduction of Energy Use}

Dietz et al. (2013) notes that describing options in a way that overcomes individuals' reluctance to incur the upfront costs associated with the proposed measure can encourage households to adopt energy efficient measures or invest in new energy technologies. For example, choice architecture can be applied to the decision facing the Watt family with respect to installing solar panels in their house.

\section{Framing the Problem}

It is important to recognize that different subsets of individuals may be receptive to different messages when considering energy efficient measures. Recent research has indicated the effectiveness of highlighting indirect and direct benefits (e.g., being "green," energy independence, saving money) in people's adoption of energy efficiency measures to address the broad range and heterogeneity in people's goals and values that contribute to the subjective utility of different courses of action (Jakob 2006). The fact that many of these co-benefits are more immediate also helps in light of the hyperbolic discounting of delayed benefits. A crisis like the Juneau, Alaska, power outage is an example, making energy scarce and sending a strong price signal for conservation.

The importance of political identity considerations also plays a role, as different constituencies have different associations to choice options. More specifically, promoting the environment can negatively affect adoption of energy efficiency due to the political polarization surrounding environmental issues. A study by Gromet et al. (2013) revealed

that more politically conservative individuals were less likely to purchase a more expensive energy-efficient light bulb when it was labeled with an environmental message than when it was unlabeled. An earlier related study by Hardisty et al. (2010) showed that a label for a carbon fee to which most people have positive associations (i.e., "carbon offset" which allows for guilt-free air travel) increases consideration and purchase of the fee, whereas a label with a negative associations (i.e., "carbon tax," which has strong 
negative associations among conservative respondents) has the opposite effect, holding material costs and benefits constant.

\section{Using Choice Defaults}

Making one choice alternative the default option so that it will be in place if no other option is actively chosen has been shown to be effective by a wide range of lab studies (e.g., Johnson et al. 2007; Weber et al., 2007) and evidence from the field ranging from insurance decisions (Johnson et al. 1993) to organ donation (Johnson and Goldstein 2003). Economists (Choi et al. 2003) and psychologists (Weber and Johnson, 2009) agree that multiple reasons contribute to this effect, including decision makers' inertia, implied endorsement of the default option, and the tendency to process this option earlier and more favorably than other alternatives (Johnson et al. 2007, Weber et al. 2007).

Heterogeneity in decision makers' preferences and circumstances present a challenge in selecting defaults since there may not be one option that would increase every person's welfare if it were the one chosen. Goldstein et al. 2008 has addressed this issue by exploring the use of smart defaults, i.e., customized default options in response to a consumer's answers to a small number of diagnostic questions.

Energy-efficient and green-energy choice options can be presented to households in a variety of ways that increase their likelihood of being selected. One way is to list the energy-efficient appliances at the top of a list of products in a given category, or to provide lists or matrices of products presorted by energy efficiency rather than by manufacturer or by price (Johnson et al. 2012). Making energy-efficient products or technology the no-choice default, for example in building codes, is another way to increase uptake of such technology. The choice of CFL bulbs increased from 56 percent to 80 percent when CFL bulbs were provided as the no-choice lighting default in a house renovation rather than incandescent bulbs (Dinner et al. 2011). This still gives decision makers choice autonomy should they want to override the specified default.

The same behavior has been observed when choosing between different providers of electricity. For example, making green energy (rather than conventional carbongenerated energy) the default option resulted in a very large percentage of German utility customers accepting and staying with this option even when feedback about its higher 
costs was experienced for several months after the intervention (Pichert and Katsikopoulus 2008). ${ }^{6}$

\section{Structuring Economic Incentives}

Given that households are unlikely to choose energy-efficient technology in the absence of short-term economic incentives, solar companies that are trying to expand their market might consider paying the upfront cost of the panels so there would be no initial expenditure by the Watt family. The company would then issue a loan tied to the mortgage, so that the cost of the solar panels will be repaid over the next fifteen, twenty or thirty years by the property owner. Solar companies in California such as Stellar Solar have a program similar to this one (http://www.stellarsolar.net/residential-solar-panelinstallation-san-diego.html).

The company would also provide accurate information to households on their annual savings relative to what their energy bill would have been without solar panels, either after the household signed up or before, telling them about the savings they are currently missing. These homeowners could then compare these savings with their annual loan payments to the solar company, because the two amounts are being provided in a comparable metric (i.e., annual amount). The solar company could also guarantee that the monthly annual loan costs would always be lower than the savings in energy costs, thus creating solar investment as a dominating alternative. Portions of the loan payments could be deferred to the next month or the loan extended, so the household would be guaranteed to save money each month (Montgomery 1989).

\section{Establishing Social Norms}

Individuals' and households' decisions about energy use are sensitive to choice architecture. For example, the company OPOWER has been highly successful in encouraging energy efficiency by issuing reports that compare households' energy usage among neighbors with similarly-sized houses and also include targeted tips for

\footnotetext{
${ }^{6}$ From a social welfare perspective it may be appropriate to make green energy the default option only if the estimated cost of carbon is sufficiently high. Borenstein (2012) calculated that residential solar would be cost competitive only on a social cost basis in the USA, if the cost of carbon dioxide emissions were greater than $\$ 316$ per ton.
} 
households to lower their energy consumption to the "normal" neighborhood rate. Using data from a randomized natural field experiment of 600,000 households, Allcott (2011) estimates that OPOWER's Home Energy Report letters to residential utility customers that provide descriptive norms by comparing their electricity use to that of their neighbors reduce energy consumption by 2.0 percent, with a 6.3 percent reduction for the highest use decile and a 0.3 percent reduction for the lowest decile. These non-price intervention effects are equivalent to that of a short-run electricity price increase of 11 to 20 percent, and their cost effectiveness compares favorably to that of traditional energy conservation programs. ${ }^{7}$

Following a social norm can be seen as a specific decision simplification that substitutes a rule ("I do what similar others do") for any implicit or explicit calculation of costs and benefits (Weber and Lindemann 2007). Such rules and social-role related obligations are often acquired through observational learning and imitation. Copying the observed behavior of others is a widespread phenomenon of which the imitator is typically unaware and plays a large role in human development (Meltzoff and Moore 1999).

If social norms are established that lead to greater use of energy efficient technology at the household level, this effect will cross to a more macro level by encouraging manufacturers to invest into the R\&D of such technology and by encouraging public sector actions such as well-enforced standards of energy efficiency as part of building sale requirements as have been practiced in Davis, CA for thirty years (Dietz et al. 2013).

\subsection{Adaptation Measures for Flood Reduction}

A combination of choice architecture measures and short-term economic incentives may lead individuals and households to invest in flood adaptation measures.

\footnotetext{
${ }^{7}$ Allcott points out that there is an unambiguous gain in consumer welfare from the OPOWER program if the treatments affect energy use by improving information or facilitating social learning about privatelyoptimal levels of energy use. If on the other hand, the treatments affect only the moral utility of energy use (i.e., happy feeling when reducing energy use and contributing to a public good such as reduced GHG emissions, or guilt when increasing energy use), then it is not clear whether they are consumer-welfare enhancing.
} 


\section{Framing the Problem}

Research reveals that people are willing to pay considerably more to reduce the risk of adverse events if the likelihood of the event is taken seriously rather than being viewed as below one's threshold level of concern. One way to do this is to use a longer time horizon for estimating the probability of an event. People are more willing to wear seat belts if they are told they have a cumulative .33 chance of a serious car accident over a fifty-year lifetime of driving rather than a .00001 chance each trip (Slovic et al. 1978). Property owners are far more likely to take flood risk seriously if they are told the chance of at least one flood during a 25-year period is 1 in 5 rather than the comparable annual probability of 1 in 100 (Weinstein et al. 1996). Such information provision programs could be supported by insurers and real estate brokers (programs targeted to their clients) and local, state and federal governments.

One can also focus on the benefits of protection against specific events rather than on a generic class of events. Controlled experiments years before the terrorist attacks of 9/11 revealed that consumers are willing to pay more for insurance against a plane crash only caused by terrorists than for a crash due to any cause (Johnson et al. 1993). This finding suggests that citing the benefits of protecting oneself against another hurricane such as Sandy might be more successful in attracting interest than a message framed merely in terms of reducing future flood damage.

\section{Structuring Economic Incentives}

Coupling home improvement loans with flood insurance could provide economic incentives for homeowners to engage in flood damage prevention. Similar to the choice architecture for encouraging adoption of solar energy, long-term home improvement loans could spread the cost of the adaptation measure over a period of years, which would diminish consumers' reluctance to invest in adaptation measures caused by a focus on short-term horizons and hyperbolic discounting (Kunreuther, Meyer and Michel-Kerjan 2013). Homeowners who invested in adaptation measures would be given an insurance premium discount to reflect the reduction in expected losses from floods.

To illustrate how the Lowlands could employ such a program, consider the example presented in Section 2 illustrating the outcomes of investing in flood adaptation 
if the family utilized expected utility theory in making their decisions. If flood insurance premiums reflected risk, the reduction in the annual insurance premium would be $\$ 400$ [i.e., .01 $(\$ 40,000)]$. The adaptation measure costs $\$ 1,200$, but with a five-year home improvement loan at an annual interest rate of 10 percent, the yearly loan payment will be only $\$ 295$. The Lowlands would thus save $\$ 105$ each year by adopting this measure, presumably making it an attractive alternative.

The home improvement loan and a multi-year flood insurance policy could be tied to the property rather than to the homeowner. This measure would avoid cancellations of insurance, as happens with flood insurance when individuals have not experienced damage for several years. ${ }^{8}$ Homeowners even allow their flood insurance to lapse when they are required to purchase flood insurance as a condition for a federally insured mortgage. Some banks and financial institutions have not enforced this regulation, possibly because mortgages are transferred to financial institutions in non-flood prone regions of the country that are not aware of either the flood hazard risk or the requirement that homeowners may have to purchase this coverage (Michel-Kerjan et al. 2012).

\section{Conclusions and Future Research}

This paper highlights the importance of understanding individuals' perception of risk and the heuristics they utilize in making choices as it affects their decisions to invest in costeffective adaptation and mitigation measures.

Empirical research in psychology and behavioral economics provides a large body of evidence that people frequently engage in intuitive thinking that leads to decisions that differ from those implied by formal models such as expected utility theory. Recognizing these behavioral characteristics of individuals provides entry points for designing strategies, such as linking choice architecture measures with short-term economic incentives.

\footnotetext{
${ }^{8}$ See Kunreuther, Pauly and McMorrow (2013) for more details on the role that insurance can play to encourage investment in adaptation measures by utilizing formal models of choice while taking into account the features of intuitive thinking.
} 
Future research could examine the impact that strategies encouraging individuals to invest in adaptation measures will have on social welfare, as this has important implications for government policy. Another question is whether the public sector can influence decision making through subsidies, fines and tax incentives coupled with enforcement of building codes. An examination of these policy tools in combination with choice architecture may provide the structure and components for developing a theory of behavioral welfare economics that addresses ways to increase individuals' investments in mitigation and adaptation measures as it relates to climate change and other social problems. 


\section{References}

Allcott, H. (2011). Social norms and energy conservation. Journal of Public Economics, 95, no. 9: 1082-1095.

Borenstein, S. (2012). The Private and Public Economics of Renewable Electricity Generation. Journal of Economic Perspectives, 26(1): 67-92.

Bostrom, A., Morgan, M. G., Fischhoff, B., \& Read, D. (1994). What do people know about global climate change? 1. Mental models. Risk Analysis, 14, 959-970.

Choi, J. J., Laibson, D., Madrian B. C. \& Metrick, A. (2003). Optimal defaults. Behavioral Economibs, Public Policy, and Paternalism, 93, 180-185.

Creyts, J., Granade, H. C., \& Ostrowski, K. J. (2010). U.S. energy savings: Opportunities and challenges. McKinsey Quarterly, January Issue.

Cullen, H. (2010). The weather of the future: heat waves, extreme storms, and other scenes from a climate-changed planet. New York: Harper.

Denholm, P., Margolis, R. M., Ong, S., \& Roberts, B. (2009). Break-even cost for residential photovoltaics in the United States. Key drivers and sensitivities. National Renewable Energy Lab, Technical Report NREL/TP-6A2-46909.

Dietz, T., Stern, P. C., \& Weber, E. U. (2013). Reducing carbon-based energy consumption through changes in household behavior. Daedalus, 142, 1-12.

Dinner, I., Johnson, E. J., Goldstein, D. G., \& Liu, K. (2011). Partitioning default effects: Why people choose not to choose. Journal of Experimental Psychology: Applied, 17, no. 4332 .

Drury, E., Jenkins, T., Jordan, D., \& Margolis, R. (2013). Photovoltaic investment risk and uncertainty for residential customers. IEEE Journal of Photovoltaics.

Frederick, S., Loewenstein, G., \& O’Donoghue, T. (2002). Time discounting and time preference: A critical review. Journal of Economic Literature, 40, 351-401.

Gately, D. (1980). Individual discount rates and the purchase and utilization of energyusing durables: Comment. The Bell Journal of Economics, 11, 373-374. 
Goldstein, D.G., Johnson, E. J., Herrmann, A., \& Heitman, M. (2008). Nudge your customer toward better choices. Harvard Business Review, December, 99-105.

Goodnough, A. (2006). As hurricane season looms, state aim to scare. The New York Times, May 31.

Gromet, D. M., Kunreuther, H., \& Larrick, R. P. (2013). Political identity affects energy efficiency attitudes and choices. PNAS, vol. 110 | no. 23 9314-9319.

Hardisty, D. J., Johnson, E. J., \& Weber, E. U. (2010). A dirty word or a dirty world? Attribute framing, political affiliation, and query theory. Psychological Science, 21, no. 1 (2010): 86-92. doi: 10.1177/0956797609355572.

Hausman, J. (1979). Individual Discount Rates and the Purchase and Utilization of Energy-Using Durables. The Bell Journal of Economics, 10, no. 1, 33-54.

Hertwig, R., Barron, G., Weber, E. U., \& Erev, I. (2004). Decisions from experience and the effect of rare events in risky choice. Psychological Science, 15, no. 8, 534-539.

Hirst, E., \& Brown, M. (1990). Closing the efficiency gap: barriers to the efficient use of energy. Resources, Conservation and Recycling, 3(4), 267-281.

Jaffe, A. B., \& Stavins, R. N. (1994). The energy-efficiency gap: What does it mean? Energy Policy, 22(10), 804-810.

Jakob, M. (2006). Marginal costs and co-benefits of energy efficiency investments: The case of the Swiss residential sector. Energy Policy, 34, no. 2, 172-187.

Johnson, E. J. \& Goldstein, D. (2003). Do defaults save lives? Science, 302, 1338.

Johnson, E. J., Häubl, G., \& Keinan, A. (2007). Aspects of endowment: a query theory of value construction. Journal of Experimental Psychology: Learning, Memory, and Cognition 33, no. 3, 461-474.

Johnson, E. J., Hershey, J., Meszaros, J., \& Kunreuther, H. (1993). Framing, probability distortions, and insurance decisions. Journal of Risk and Uncertainty, 7, no. 1, 35-51.

Johnson, E. J., Shu, S. B., Dellaert, B. C. G., Fox, C., Goldstein, D. G., Häubl, G., Larrick, R. P. et al. (2012). Beyond nudges: Tools of a choice architecture. Marketing Letters, 1-18. 
Kahneman, D. (2003). A psychological perspective on economics. The American Economic Review, 93, no. 2. 162-168.

Kahneman, D. (2011). Thinking, fast and slow. New York: Farrar, Straus and Giroux.

Kempton, W. (1991). Public understanding of global warming. Society \& Natural Resources 4, no. 4, 331-345.

Kunreuther, H., Meyer, R. J., \& Michel-Kerjan, E. (2013). Overcoming Decision Biases to Reduce Losses from Natural Catastrophes. In: E. Shafir (Ed.), Behavioral Foundations of Policy, Princeton University Press.

Kunreuther, H., Pauly, M. V., \& McMorrow, S. (2013). Insurance and Behavioral Economics: Improving Decisions in the Most Misunderstood Industry. New York: Cambridge University Press.

Laibson, D. (1997). Golden eggs and hyperbolic discounting. The Quarterly Journal of Economics, 112, no. 2, 443-478.

Leighty, W., \& Meier, A. (2010). Short-term Electricity Conservation in Juneau, Alaska: A Study of Household Activities. Proceedings of the 2010 Summer Study on Energy Efficiency in Buildings. Washington, DC: ACEEE, eec.ucdavis.edu/aceee/2010/data/papers/2131.pdf.

Loewenstein, G. F., Weber, E. U., Hsee, C. K., \& Welch, N. (2001). Risk as feelings. Psychological Bulletin, 127, no. 2: 267.-286.

Meltzoff, M. A., \& Moore. M. K. (1999). Persons and representation: Why infant imitation is important for theories of human development. In: J. Nadel and G. Butterworth, (Eds.), Imitation in Infancy. Cambridge, UK: Cambridge University Press, 1999.

Meyer, E., Baker, J., Broad, K., Czajkowski, J., \& Orlove, B. (2013). The Dynamics of Hurricane Risk Perception: Real-Time Evidence from the 2012 Atlantic Hurricane Season. Wharton Risk Center Working Paper \#2013-07. 
Michel-Kerjan, E., Lemoyne de Forges, S., \& Kunreuther, H. (2012). Policy tenure under the U.S. National Flood Insurance Program (NFIP). Risk Analysis, 32, no. 4 (2012): 644-658.

Mills, B. F., \& Schleich, J. (2008). Why don't households see the light? Explaining the diffusion of compact fluorescent lamps. Working paper sustainability and innovation, No, S1/2008, http://nbn-resolving.de/urn:nbn:de:0011-n-84564.

Montgomery, H. (1989). From cognition to action: The search for dominance in decision making. In: H. Montgomery \& O. Svenson (Eds.), Process and Structure in Human Decision Making (pp. 23-49). New York: Wiley.

Palm, R. (1995). Earthquake insurance: A longitudinal study of California homeowners. Westview Press.

Patt, A., \& Weber, E. U. (2013). Perceiving and communicating climate change uncertainty. WIREs: Climate Change. Doi 10.1002/wcc.259.

Peters, E., \& Slovic, P. (2000). The springs of action: Affective and analytical information processing in choice. Personality and Social Psychology Bulletin, 26, no. $12,1465-1475$.

Pichert, D., \& Katsikopoulos, K. V. (2008). Green defaults: Information presentation and pro-environmental behaviour. Journal of Environmental Psychology, 28, no. 1, 63-73.

Reynolds, T. W., Bostrom, A., Read, D., \& Morgan, M. G. (2010). Now what do people know about global climate change? Survey studies of educated laypeople. Risk Analysis, 30, no. 10, 1520-1538.

Simon, H. (1957). Models of Man. New York, NY: John Wiley.

Slovic, P. (1987). Perception of risk. Science, 236, 280-285.

Slovic, P., Fischhoff, B., \& Lichtenstein, S. (1978). Accident probabilities and seat belt usage: A psychological perspective. Accident Analysis \& Prevention, 10, 281-285.

Solomon, S., Plattner, G.-K., Knutti, R., \& Friedlingstein, P. (2009). Irreversible climate change due to carbon dioxide emissions. Proceedings of the national academy of sciences 106 , no. 6, 1704-1709. 
Spence, A., Poortinga, W., Butler, C., \& Pidgeon, N. F. (2011). Perceptions of climate change and willingness to save energy related to flood experience. Nature Climate Change, 1, no. 1, 46-49.

Sterman, J. D., \& Sweeney, L. B. (2007). Understanding public complacency about climate change: Adults' mental models of climate change violate conservation of matter. Climatic Change, 80, no. 3 (2007): 213-238.

Thaler, R. (1999). Mental accounting matters. Journal of Behavioral Decision Making, 12, 183-206.

Thaler, R., \& Sunstein, C. (2008). Nudge: The gentle power of choice architecture. New Haven, CT: Yale University Press.

Tversky, A., \& Kahneman, D. (1991). Loss aversion in riskless choice: A referencedependent model. The Quarterly Journal of Economics 106, no. 4, 1039-1061.

Weber, E. U. (2006). Experience-based and description-based perceptions of long-term risk: Why global warming does not scare us (yet). Climatic Change, 77, no. 1, 103 120.

Weber, E., \& Johnson, E. (2009). Mindful judgment and decision making. Annual Review of Psychology, 60, 53-85.

Weber, E. U., Johnson, E. J., Milch, K., Chang, H., Brodscholl, J., \& Goldstein, D. (2007). Asymmetric discounting in intertemporal choice: A query theory account. Psychological Science, 18, 516-523.

Weber, E. U., \& Lindemann, P. G. (2007). From intuition to analysis: Making decisions with our head, our heart, or by the book. In: H. Plessner, C. Betsch \& T. Betsch (Eds.), Intuition in judgment and decision making (pp. 191-208). Mahwah, NJ: Lawrence Erlbaum.

Weber, E.U., \& Stern, P. (2011). The American public's understanding of climate change. American Psychologist, 66, 315-328. doi: 10.1037/a0023253.

Weinstein, N. D., Kolb, K., \& Goldstein, B. D. (1996). Using time intervals between expected events to communicate risk magnitudes. Risk Analysis, 16, no. 3: 305-308. 
